\title{
THERMAL ANALYSIS OF HEAT EXCHANGER IN THE NANO FLUID(CUO-W) IN THE SHELL TUBE HEAT EXCHANGER
}

\author{
Ricky Johnson Ganta \\ Department of Mechanical engineering \\ Student, \\ ICFAI Foundation for Higher Education, \\ Hyderabad
}

\begin{abstract}
Heat exchanger is the device transforming the heat from one fluid to another fluid. Nano fluids are engineered by the nanometer sized particles. Nanofluids can be in the form of oxides and nitrides. The main motive is to determine heat transfer characteristics heat transfer like Reynolds number, thermal conductivity, heat transfer coefficient under the volume concentration in the base fluid and nano fluid. It is used in the shell tube heat exchanger. Thermal Analysis is performed at various positions with the assumption of discharge. The heat transfer coefficient is higher in the nano fluid compared to the base fluid. It is beneficial in the conservation of energy and heat exchanger material. $\mathrm{CuO}-\mathrm{W}$ is preferred as nanofluid in the current study.
\end{abstract}

Keywords - Nano Fluids, Oxides, CuO-W, Thermal Analysis, Heat transfer coefficient

Problem Definition: Leaking of combustion gases, appearance of crack from the corrosion and wearing down the metal of the component. Any crack or hole that is big enough to affect combustion will be easily visible to the naked eye. When the cause occur in the heat exchanger we must replace the heat exchanger with the proper dimensions of the furnace which is the center of the furnace.

\section{INTRODUCTION}

p The implementation of Nano fluids in the heat exchangers in the various industries. Low thermal conductivity is the primary drawback for the expansion of energy efficient heat transfer which is vital for cooling purpose. Nano fluids are engineered by nano particles with average size of $100 \mathrm{~mm}$ in the heat transfer fluids such as water, ethylene glycol. The main plot in the utilisation of thermo fluids in the heat exchangers minimize the size of the heat transfer equipment. Nano fluids are applicable in the conservation of heat energy and heat exchanger material. The nanoparticles can transport and properties of the thermo fluid. Authors and Researchers have investigated heat exchangers in the nano fluids in the path way of chemical approach balancing the equation in finding the

\author{
Avinash Malladi \\ Department of Mechanical engineering \\ Faculty of Science and technology \\ ICFAI Foundation for higher education, \\ Hyderabad
}

volume fraction in terms of moles. Thermal and CFD analysis have implemented in the shell tube heat exchangers with the assumptions of cases.

H.Chao and H.Jiang(2014) performed on "Effect of Temperature on the effective thermal conductivity of $n$ tetracedene based nanofluids containing copper

nanoparticles". In this study they assumed n-tetracedene as the nanofluid. Thermal conductivity was estimated for the volume fractions ranging from 0.00001 to 0.02 and temperatures from $306.22 \mathrm{k}$ to391.06k. Thermal conductivity was decreased after exceeding the $391.06 \mathrm{~K}$ than compared to 306.22 and $360.71 \mathrm{~K}$. Thermal resistance increased with increase in temperature. Thermal conductivity was more at the $452.66 \mathrm{k}$ in case of base fluid due nanoconvection induced by nanoparticle at high temperature. Luna.I and Chowdary.Z(2015) examined on "Measurement of Forced Heat Transfer Coefficent low volume fraction CuO-PVA Nanofluids under laminar flow condition". Different samples were assumed for the volume concentration varying from 0.05 to 0.2 with the mean of 0.5 . It was prepared with the dispersion of CuO-PVA with an average size of $32.5 \mathrm{~mm}$ with the

Ultrasonic machining and Magnetic Stirring. Forced heat transfer coefficient quantified with the help of Vertical Shell Tube Heat with a laminar flow $<2300$. It was increase in the heat transfer coefficient nanofluid contrast to base fluid. I.Sharrual and R.Saidur(2016) studied on" Experimental investigation on $\mathrm{Al} 2 \mathrm{O} 3-\mathrm{W}, \mathrm{SiO} 2-\mathrm{W}$ and $\mathrm{ZnO}-\mathrm{W}$ nanofluids and their application in a shell and tube heat exchanger", They determined the performance of Shell tube and Heat exchanger with Nanofluids in the experimental path with the assumption of two cases. In the case- 1 at constant with fluid flow of 4lpm with other different fluid from 2 to $81 \mathrm{pm}$. Highest performance was observed with fraction volume of $0.3 \%$ at $61 \mathrm{pm}$ of $\mathrm{ZnO} 2$.Similarly it was found at $7 \mathrm{lpm}$ with fraction volume of $0.5 \%$. In case- 2 highest performance was observed at $81 \mathrm{pm}$ in all the nano fluids. There was improvement of $35 \%$ by $\mathrm{ZnO}-\mathrm{W}(\mathrm{PVP})$ nano fluid. Apart from that highest performance in case of $\mathrm{ZnO} 2-\mathrm{W}$ and least in case of SiO2-W. Ramtin Barzegarian and Tooraj Yousefi(2017) examined on "Thermal 
performance augmentation using water based Al2O3-gamma nanofluid in a horizontal shell and tube heat exchanger under forced circulation" In this paper some elements in the hot working fluid includes Reynolds number, volume concentration on heat Characteristics and thermal performance of heat exchanger is investigated. Results indicate

that with increment of Nusselt number $9.7 \%, 20.3 \%$ and 29.8 at volume concentration of $0.03 \%, 0.15 \%$ and $0.30 \%$. and overall heat transfer coefficient of $5.4 \%, 10.3 \%$ and $19.1 \%$.

Based on the results they concluded that with the implementation of nanofluid at minimum and maximum 0.03 and 0,3 , thermal performance factor $6.5 \%$ and $18.9 \%$ was evaluated and compared with base fluid. Khan.Z and Khan.Z.A(2018) investigated on "Experimental and numerical investigations of nano-additives enhanced paraffin in a shelland-tube heat exchanger" Metal Oxides, Metal Nitrides and Carbon Allotropes are nano additives on thermal conductivity and thermal storage of paraffin based latent heat were investigated in the pathway of experimental and numerical. Thermal performance were traced out by supercharging and discharging the shell tube heat exchanger at the operating conditions. Numerical analysis were examined on the viscosity, heat transfer coefficient and compared with paraffin. From the results it was observed that there was increase in volume fraction from 1 to $3 \%$. The optimum value $3 \%$ was established with the enhancement of LHS system in practical applications.

\section{Heat exchanger using Nano fluid}

A heat exchanger model is shown below in the figure 1 . The heat transfer rate in the heat exchanger using base fluid and Nano-fluid is studied.

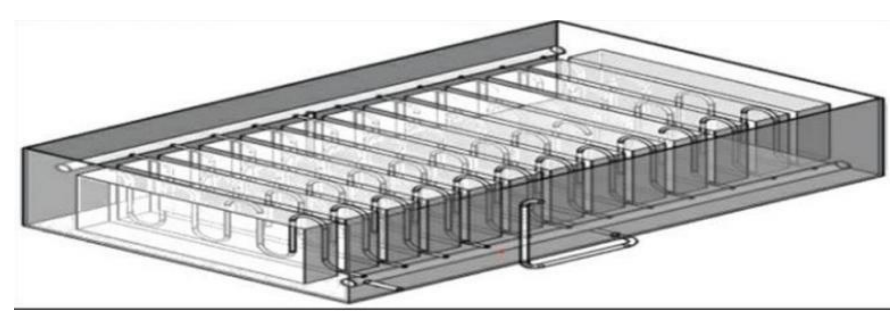

Fig 1: Heat Exchanger by Nano fluid.

\begin{tabular}{|l|l|}
\hline Shell diameter & $225 \mathrm{~mm}$ \\
\hline Shell length & $900 \mathrm{~mm}$ \\
\hline Tube outer diameter & 18 \\
\hline Tube inner diameter & 15 \\
\hline
\end{tabular}

\begin{tabular}{|l|l|}
\hline No of tubes & 16 \\
\hline
\end{tabular}

Specification of heat

\section{Thermal conduction $\left(\mathrm{W} / \mathrm{m} .{ }^{\circ} \mathrm{C}\right)$}

Thermal conduction is calculated from relationships of Nanofluids gift within the literature. Therelationship is chosen counting on the sort of Nano-fluids used, temperature and volume concentration of nanoparticles

$\mathrm{Knf}=\mathrm{Kbf}+\operatorname{Kbf}[3.761 \varnothing+0.0179 \mathrm{~T}-0.307]$

\section{Coefficient (Pa.s):}

Dynamic viscosity is calculated from relationships of Nanofluids gift within the literature.

Therelationship is chosen counting on the degree concentration of nanoparticle and also the dynamicviscosity of base fluid. the overall formula in keeping with

$\mu \mathrm{nf}=(1+2.5 \emptyset) \mu \mathrm{bf}(2)$

\section{Density:(kg/m3)}

The density of base fluid and density of nanoparticles $(\mathrm{CuO})$ for various volume fractions area unit calculated exploitation density relationships obtainable for Nano-fluids

$\rho n f=\varnothing \rho p+(1-\varnothing) \rho b f(3)$

\section{Specific}

The specific heat is an element of the vital characteristics in influencing heat transfer rate ofNano-fluids. heat energy may be calculated exploitation the equation assuming equilibrium between the bottom fluid and also nanoparticles

$\mathrm{Cpnf}=\emptyset \rho p \mathrm{Cpp}+1-\emptyset \rho b f \times \operatorname{Cpbf} \times$ x $\rho f(4)$

Volume concentration of nanoparticle in base fluid can be calculated by applying the following Equation

Volume Concentration $\varnothing \%=\mathrm{mxCuO}$

$$
\begin{gathered}
\rho x \mathrm{CuO} \\
\mathrm{mCuO}+\mathrm{mbf} \\
\rho \mathrm{CuO} \rho b f
\end{gathered}
$$

The average temperature inside the battery and its compartment are shown in the below figure 2 . The Nano fluid used inside reaches $18^{\circ} \mathrm{C}$. The maximum temperature recorded inside the heat exchanger is $31^{\circ} \mathrm{C}$ during the 13 minutes of operation. 


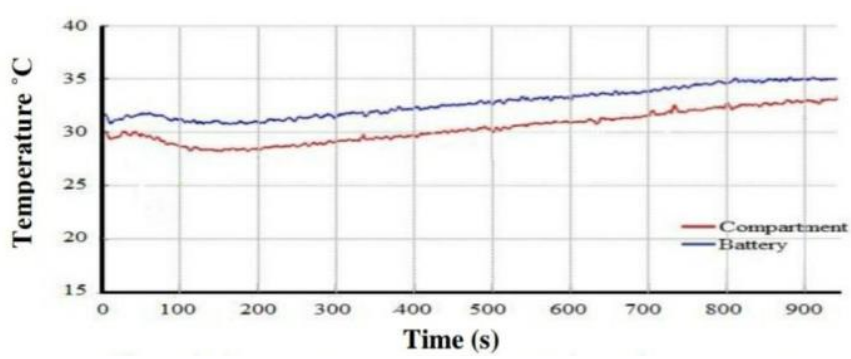

Fig 2: Average temperatures for batteries and compartment.

The Nano fluid from the heat exchangers exit temperature can be computed by

$\mathrm{Te}=\mathrm{Ts}-\mathrm{Ts}-\mathrm{Ti} \exp -\mathrm{h} \times$ Asi $/ \mathrm{m} . \times \mathrm{Cp}](6)$

The bulk mean temperature:

$\mathrm{Tb}=(\mathrm{Ti}+\mathrm{Te}) / 2(7)$

Reynolds number is calculated by

$\operatorname{Renf}=(\rho \mathrm{Vm} \operatorname{di}) / \mu \mathrm{nf}(8)$

If the flow of Nano fluid is placed in a single row of pipes placed transversely as shown in the figure 3 . The mean velocity is

$\mathrm{Vm}=\mathrm{V}[1-(\pi \mathrm{d} / 4 \mathrm{~s} 1)](9)$

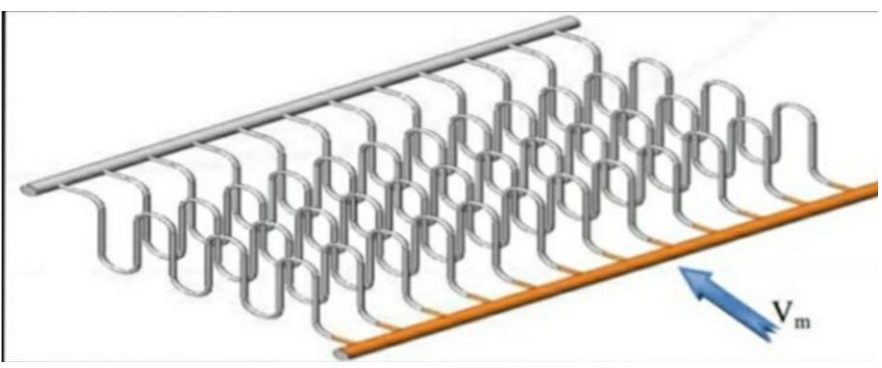

In this study the laminar flow is involved in the circular tube with uniform surface temperature. The nusselt number of a Nano fluid is

Nunf $=0.4329(1+11.285 \varnothing 0.754$ Pe 0.218$)$ Renf 0.333 Prnf0.4

The head loss in heat exchanger is calculated from Darcy's equation

$\mathrm{hL}=(f \mathrm{~L} \mathrm{~V} 2) / 2 \mathrm{~g}$ di (11)

From moody' diagram, the friction factor and the pressure drop can be calculated

$\Delta \mathrm{P}=\mathrm{g} \rho \mathrm{hL}(12)$
The value of heat transfer coefficient can be calculated by nusselt number

hnf $=$ Nu Knf / di (13)

Rate of heat transfer for a base fluid, Nano fluid can be expressed by following relation

$\mathrm{Q}=\mathrm{h} \mathrm{A} \Delta \mathrm{T}(14)$

\section{INPUT DATA}

This study shows the idea of heat transfer process between the ambient for battery environment and a heat exchanger which is made of copper tube. In fig 1 basic concept is explained. The coil is of diameter $\mathrm{D}=6.5 \mathrm{~mm}$ and the number of coils are 12 in number with length $1.4 \mathrm{mt}$. The thermophysical properties of both base fluid as well as Nano fluid are taken at an average temperature of $23.5^{\circ} \mathrm{C}$ of coils.

\begin{tabular}{|l|l|l|}
\hline $\begin{array}{l}\text { Thermophysical } \\
\text { properties }\end{array}$ & Base fluid & $\begin{array}{l}\text { Nano } \\
\text { fluid }\end{array}$ \\
\hline Density kg/m³ & 1000 & 77.20 \\
\hline $\begin{array}{l}\text { Dynamic } \\
\text { viscosity kg/m.s }\end{array}$ & $9.10 \times 10-4$ & $9.78 \times 10-3$ \\
\hline $\begin{array}{l}\text { Thermal } \\
\text { conductivity } \\
\text { W/m. }{ }^{\circ} \mathrm{c}\end{array}$ & 0.6073 & 0.8209 \\
\hline $\begin{array}{l}\text { Specific heat } \\
\mathrm{J} / \mathrm{kg} .{ }^{\circ} \mathrm{C}\end{array}$ & 4.180 & 4.054 \\
\hline
\end{tabular}

Table-1 Thermo Properties of Fluid

\section{RESULT}

This analysis is used to improve the heat transfer process which the main factor is determining the thermophysical properties of Nano-fluid as calculated in the above equations (size of nanoparticles and base fluid type)

It is true that there are improvements in thermal conductivity, dynamic viscosity and density of Nano fluid, the specific heat is decreased in the comparison with base fluid as shown in the table 1. The Heat transfer coefficient and heat transfer rate of Nano fluid can be improved. There is small increasing pressure drop in comparison with base fluid. 


\begin{tabular}{|l|l|l|}
\hline Results & Base Fluid & Nano fluid \\
\hline $\begin{array}{l}\text { Total head } \\
\text { losses(m) }\end{array}$ & 4.86 & 4.96 \\
\hline $\begin{array}{l}\text { Total pressure } \\
\text { drop (KPa) }\end{array}$ & 47.08 & 38.70 \\
\hline $\begin{array}{l}\text { Heat transfer } \\
\text { coefficient } \\
\left(\mathrm{W} / \mathrm{m}^{2} .{ }^{\circ} \text { ) }\right.\end{array}$ & 5.250 & 5.394 \\
\hline $\begin{array}{l}\text { Heat transfer rate } \\
(\mathrm{KW})\end{array}$ & 12.44 & 12.78 \\
\hline
\end{tabular}

Table-2 Results of Base and Nano Fluid on Thermo fluid

Also there is increase in Nusselt number and Reynolds number of Nano-fluid. There is decrease in the the prandtl number and Peclet number in comparison with base fluid

\begin{tabular}{|l|l|l|}
\hline Types & Base Fluid & Nano fluid \\
\hline Reynolds number & 3956 & 2322.6 \\
\hline Prandtl number & 6.26 & 4.82 \\
\hline Peclet number & 14000 & 12378 \\
\hline Nusselt number & 7780.33 & 5913.75 \\
\hline
\end{tabular}

Table-3 Results of Base and Nano Fluid on Convection

\section{Example of Audi E-Tron which uses heat pump to maintain battery temperature}

Audi E-Tron uses the heat pumps to main the temperature of the battery which keeps the battery in optimal temperature in any seasons. The car uses $95 \mathrm{Kwh}$ battery pack with the help of this heat pumps the optimum temperatures between $25^{\circ} \mathrm{C}$ to $35^{\circ} \mathrm{C}$ is maintained. Due to this the reduction in performance of accelerating is greatly reduced because they get hotter when accelerating harder this makes the motor performance reduction in power output.

This type of thermal management is better in places with irregular temperatures outside and effective battery management can be maintained.

In hot temperatures the battery is kept cooler to get optimal temperature and in cooler temperatures the battery is kept hotter to get optimal temperature which is safer for the battery and best performance with longer life can be expected.
The Manufacturer says that the cooling will work well so that this vehicle performance during aggressive driving times can be obtained and the thermal cooling system makes this possible to push the pedal over and over again without any problem in the performance in Audi E-Tron.

There are other two types of thermal management which are

1. Surface cooling system

2. Tab cooling system

Surface cooling

In this the surface of the battery is cooled by the flow of liquid

Tab cooling

In this the tabs which the situated on either side of battery are cooled with help of flow of liquid

In this study of surface and tab cooling an experiment is done in which both the system are tested. With the help of surface cooled rig and tab cooled rig. Heat sinks are used as cooling elements to each equipment and peltier elements which maintain the temperature at $20^{\circ} \mathrm{C}$ on both the rigs and the experiment is started by charging the rigs thousand times. This was repeated 3 times in total. At higher rates of discharging of battery loss of $9.2 \%$ is seen in surface cooling as compared to $1.2 \%$ in tab cooling. As this was done thousand time the discharge is increased 3 times compared to the tab cooling.

By this analysis we came to know the reason because a battery is made of several layers of chemicals so when the surface of battery is cooled only the layers which are nearer to the surface are getting cooled and the deeper layers remain hotter. But in case of tab cooling uniform cooling is observed through the battery.

\section{OBSERVATION}

By using tab cooling we can obtain more than 3 times of life time of the battery pack compared to the surface cooling battery. So using tab cooling is better than the surface cooling.

\section{ANALYSIS}

By the types of heat exchangers we studied using of tab cooling should be done in large batteries is better so that price will be lower when compared to small cells. In this tab cooling Nano fluid can be used as heat sinks to be more efficient.

By using heat exchanger in the battery in the places where the climate conditions are irrelevant so that depending of the temperature outside the battery is kept in optimal temperature whether it may be hot or cold. This is costly compared to the cooling by plates or tab cooling. But will be more effective in place with irregular temperatures 
International Journal of Engineering Applied Sciences and Technology, 2020

Vol. 5, Issue 2, ISSN No. 2455-2143, Pages 362-367

Published Online June 2020 in IJEAST (http://www.ijeast.com)

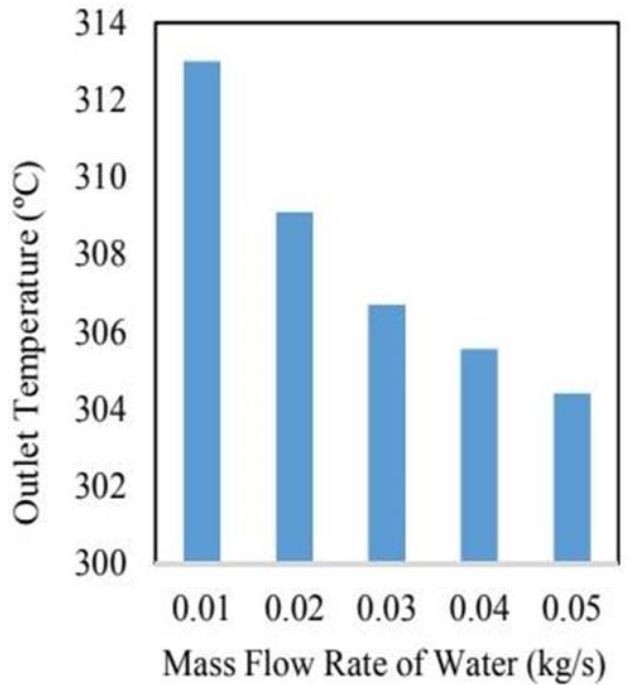

Figure-5 Mass flow rate at various outlet temperature

\section{CONCLUSION}

This Liquid cooled plate is used to eliminate the excess heat generated in the battery pack in some high temperature regions. Water is working fluid in this cooling plate system. The heat transfer analysis is done by simulating the flow of water through the heat exchanger using CFD. It is now known that excessive heat generated which can maintain the temperature in safe zones.

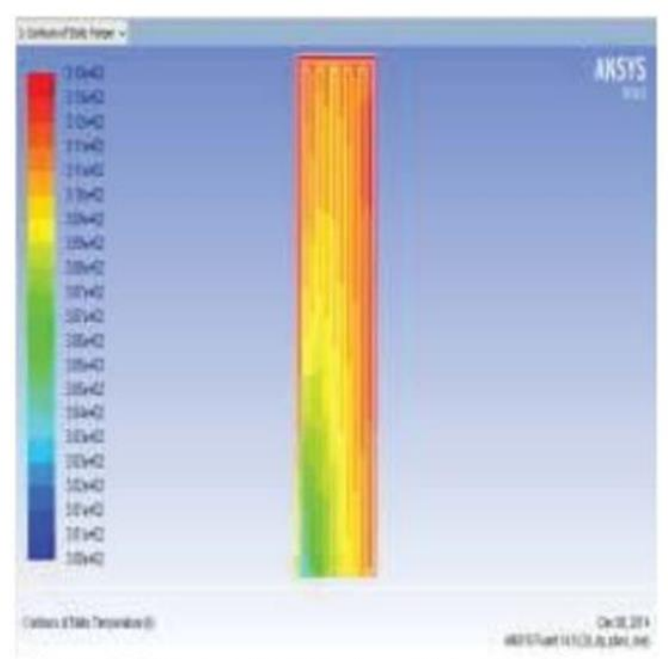

Figure 3 Temperature contour at a mass flow rate $0.03 \mathrm{~kg} / \mathrm{s}$

\section{REFERENCE}

[1]. Chao.H and Jiang.H (2014), “ Effect of Temperature on the effective thermal conductivity of n-tetracedene based nanofluids containing copper nanoparticles".Thermochim,acta pg-579.pp 27-30.

[2]. . Luna.I and Chowdary.Z(2015) "Measurement of Forced Heat Transfer Coefficent low volume fraction CuO-PVA Nanofluids under laminar flow condition". Am.J.Nanometer 3(2),pp 64-67.

[3]. Sharrual.I and Saidur.R(2016) "Experimental investigation on $\mathrm{Al} 2 \mathrm{O} 3-\mathrm{W}, \mathrm{SiO} 2-\mathrm{W}$ and $\mathrm{ZnO}-\mathrm{W}$ nanofluids and their application in a shell and tube heat exchanger", Int Journal of heat mass transfer,97,pp 547-558.

[4]. Ramtin Barzegarian and Tooraj Yousefi(2017) "Thermal performance augmentation using water based $\mathrm{Al} 2 \mathrm{O} 3$ gamma nanofluid in a horizontal shell and tube heat exchanger under forced circulation" Int communication of heat mass transfer,86,pp 52-59.

[5]. Khan.Z and Khan.Z.A(2018) "Experimental and numerical investigations of nano-additives enhanced paraffin in a shell-and-tube heat exchanger", App thermal engg,106,pp 827837.

[6]Vert, M.; Doi, Y.; Hellwich, K. H.; Hess, M.; Hodge, P.; Kubisa, P.; Rinaudo, M.; Schué, F. O. (2012). "Terminology for biorelated polymers and applications (IUPAC Recommendations 2012)". Pure and Applied Chemistry. 84 (2): 377 410. doi:10.1351/PAC-REC-10-12-04.

[7] Vert, Michel; Doi, Yoshiharu; Hellwich, Karl-Heinz; Hess, Michael; Hodge, Philip; Kubisa, Przemyslaw; Rinaudo, Marguerite; Schué, François (2012). "Terminology for biorelated polymers and applications (IUPAC Recommendations 2012)" (PDF). Pure and Applied Chemistry. 84 (2): 377 410. doi:10.1351/PAC-REC-10-12-04.

[8] Yong Chae, Seung; Kyu Park, Myun; Kyung Lee, Sang; Young Kim, Taek; Kyu Kim, Sang; In Lee, Wan (2003). "Preparation of Size-Controlled TiO2 Nanoparticles and Derivation of Optically Transparent Photocatalytic Films". Chemistry of Materials. 15 (17): 3326-3331. doi:10.1021/cm030171d.

[9] Jacques Simonis, Jean; Koetzee Basson, Albertus (2011). "Evaluation of a low-cost ceramic micro-porous filter for elimination of common disease microorganisms". Physics and Chemistry of the Earth, Parts A/B/C. 36 (14-15): 1129-1134. doi:10.1016/j.pce.2011.07.064.

[10] Batista, Carlos A. Silvera; Larson, Ronald G.; Kotov, Nicholas A. (9 October 2015). "Nonadditivity of nanoparticle interactions". Science. 350 (6257): 1242477. doi:10.1126/science.1242477. ISSN 0036-8075. PMID 26450215. 
[11]Cai.Wei,Nix.William.D. (September 2016). Imperfections in Crystalline Solids. CambridgeCore. doi:10.1017/cbo9781316389508. ISBN 9781107123137.

[12]Chen, Chien-Chun; Zhu, Chun; White, Edward R.; Chiu, Chin-Yi; Scott, M. C.; Regan, B. C.; Marks, Laurence D.; Huang, Yu; Miao, Jianwei (April 2013). "Three-dimensional imaging of dislocations in a nanoparticle at atomic resolution". Nature. 496 (7443): 74-77. Bibcode:2013Natur.496...74C. doi:10.1038/nature12009. ISSN 1476-4687. PMID 23535594.

[13]Guo.Dan; Xie.Guoxin; Luo.Jianbin (3 December 2013). "Mechanical properties of nanoparticles: basics and applications". Journal of Physics D: Applied Physics. 47 (1): 013001. doi:10.1088/0022-3727/47/1/013001. ISSN 00223727.

[14]Khan.Ibrahim; Saeed.Khalid; Khan.Idrees (1 November 2019). "Nanoparticles: Properties, applications and toxicities". Arabian Journal of Chemistry. 12 (7): 908-931. doi:10.1016/j.arabjc.2017.05.011. ISSN 1878-5352. 